\title{
(MURI 09) SEARCH FOR NEW SUPERCONDUCTORS FOR ENERGY AND POWER APPLICATIONS
}

Ivan Schuller

UNIVERSITY OF CALIFORNIA SAN DIEGO

$10 / 21 / 2014$

Final Report 


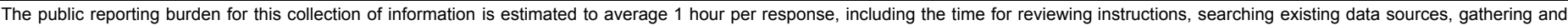

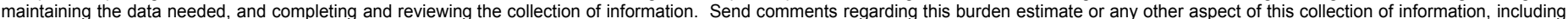

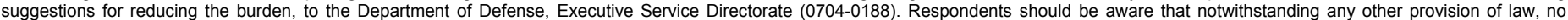
person shall be subject to any penalty for failing to comply with a collection of information if it does not display a currently valid OMB control number.

PLEASE DO NOT RETURN YOUR FORM TO THE ABOVE ORGANIZATION.
1. REPORT DATE $(D D-M M-Y Y Y Y)$
2. REPORT TYPE
$10 / 18 / 2014$
FINAL REPORT

4. TITLE AND SUBTITLE

N/A

Search for New Superconductors for Energy \& Power Applications

5b. GRANT NUMBER

FA9550-09-1-0577

5c. PROGRAM ELEMENT NUMBER

$\mathrm{N} / \mathrm{A}$

6. AUTHOR(S)

5d. PROJECT NUMBER

N/A

IVAN K. SCHULLER

5e. TASK NUMBER

$\mathrm{N} / \mathrm{A}$

5f. WORK UNIT NUMBER

N/A

7. PERFORMING ORGANIZATION NAME(S) AND ADDRESS(ES)

THE REGENTS OF THE UNIVERSITY OF CALIFORNIA, SAN DIEGO REPORT NUMBER

UC SAN DIEGO

9500 GILMAN DRIVE

LA JOLLA, CA 92093

9. SPONSORING/MONITORING AGENCY NAME(S) AND ADDRESS(ES)

AIR FORCE OFFICE OF SCIENTIFIC RESEARCH

875 NORTH RANDOLPH STREET

SUITE 325, ROOM 3112

ARLINGTON, VIRGINIA 22203-1768

10. SPONSOR/MONITOR'S ACRONYM(S)

$\mathrm{N} / \mathrm{A}$

11. SPONSOR/MONITOR'S REPORT NUMBER(S)

\section{DISTRIBUTION/AVAILABILITY STATEMENT}

\section{NO DISTRIBUTION LIMITATIONS.}

\section{SUPPLEMENTARY NOTES}

\section{ABSTRACT}

The UCSD SuperSearch for New Superconductors MURI project was dedicated to develop a novel methodology for an enlightened search for new materials, using a combination of Synthesis and Screening techniques. This project established a novel, rational methodology for the search for new superconductors in the absence of precise well-defined search methodologies. This method relies on two key ingredients; 1) synthesis of many different material combinations in one synthesis step and 2) a very sensitive detection method capable of detecting minute amounts of superconductors embedded in a non-superconducting matrix. The synthesis method had as ingredients preparations by arc-melting, powder metallurgy, high pressure synthesis sputtering, Molecular Beam Epitaxy, sol-gel and thin film techniques. The Magnetic Field Modulated Microwave spectroscopy detection method developed by us is the most sensitive detection method for superconductors. This technique is capable of detecting $10^{-12} \mathrm{cc}$ of a superconductor embedded in an other wise non-superconducting matrix. We developed the methodology described in the original proposal, discovered a large number of new superconductors, provided a search service to many researchers world wide, and continue the search in many new systems. Many young researchers educated in this field are becoming productive scientists and technologists on their own right

\section{SUBJECT TERMS}

Superconductivity, new materials, Microwave measurements, thin film materials synthesis, bulk materials synthesis.

\begin{tabular}{|c|c|c|}
\hline \multicolumn{2}{|c|}{ 16. SECURITY CLASSIFICATION OF: } \\
\hline a. REPORT & b. ABSTRACT & c. THIS PAGE \\
UU & UU & UU \\
\hline
\end{tabular}

\section{LIMITATION OF ABSTRACT}

SAR
18. NUMBER

OF
PAGES
7

19a. NAME OF RESPONSIBLE PERSON IVAN K. SCHULLER

19b. TELEPHONE NUMBER (Include area code)

858-534- 2540 
To: technicalreports@afosr.af.mil

cc: Dr. Harold Weinstock (harold.weinstock@afosr.af.mil)

Subject: FINAL Report

Grant Title: (MURI 09) Search for New Superconductors for Energy and Power Applications

Organization/Institution name: University of California, San Diego

Grant \#: AFOSR MURI \# FA9550-09-1-0577

Reporting Period: 07/15/2009-07/14/2014

\title{
Accomplishments:
}

\begin{abstract}
The search for new materials with interesting properties is probably the most challenging problem in modern condensed matter and materials physics. Important developments in the physics of condensed matter usually start with the discovery of an interesting phenomenon and it is probably safe to state that "without the material there is no physics". This extends to many interesting phenomena including magnetism, ferroelectricity, superionicity etc. Perhaps one of the most intensely explored phenomena, superconductivity, relied mostly on the almost accidental discoveries of new superconductors. The SuperSearch for New Superconductors MURI project departs from this motivated by the BAA \# 13 on "Search for New Superconductors for Energy and Power Applications". We developed a novel methodology for an enlightened search for new materials, using a combination of Synthesis and Screening techniques. While no single approach can assure the discovery of new classes of superconductors, our proposal established a rational methodology for the search for new superconductors.

We developed the methodology described in the original proposal, we have discovered a large number of new superconductors, have provided a search service to many researchers world wide, and continue the search in many new systems.
\end{abstract}

\section{EXECUTIVE SUMMARY}

The results obtained during this project include: development of unique instrumentation which will continue producing first rate science, discovery of many superconducting systems which will continue to be investigated by the members of the MURI and others, education of many young scientists (undergraduate, graduate and postdoctoral), and many collaborations nationally and internationally. A most successful project.

\section{ACCOMPLISHMENTS}

This project is dedicated to the development of new search techniques and to implement an exhaustive search for new superconductors. This project is oriented very strongly towards the search and discovery of new materials. We developed an efficient combinatorial method that allows simultaneous search for many superconducting systems. This highly interdisciplinary project was implemented using the following crucial ingredients: 1) Synthesis by many preparation methods 2) fast, sensitive and efficient methods that allow discarding the uninteresting parts of the phase diagram and 3) a comprehensive battery of tests including transport, magnetization, specific heat, optical and microwave response. 
During this project we have addressed all the aims of the proposal. Several major accomplishments include

1. The Magnetic Field Modulated Microwave Spectroscopy (MFMMS) was developed, provided extensive service to the various AFOSR MURIs working in this field and to others. The Magnetic Field Modulated Microwave Spectroscopy (MFMMS) system with its selectivity and unparalleled limit of detection of minority superconducting phases, of $10^{-12} \mathrm{cc}^{3}$ embedded in a non-superconducting matrix, has become a powerful tool for the whole community. The discoveries already made, validate the search methodology and now large searches are underway. Samples were exchanged, and coordinated measurements were done between the different MURI partners and others elsewhere. More than 2100 samples have been measured to date.

2. Joint searches using arc-melting, powder metallurgy, sputtering, sol gel and thin film techniques in a variety of possible superconducting systems with potential for new discoveries. The search methodology described in the original proposal is being applied to a variety of bulk materials systems including: mixtures of well-known superconductors, borides, carbides, silicides, and chalcogenides. In addition, a number of thin film systems have been explored: A15s, superlattices, arrays of nanodots, and phase-spread alloys. See Table I below for a list of all the systems investigated so far.

3. Unusual systems investigated. Search for new superconductors is underway in the largest collection of micrometeorites available from Susan Taylor at the Army Core of Engineers and in a variety of meteorites, lunar and martian rocks in collaboration with Prof. M. Thiemens, Chemistry Department, UCSD. Conversations (at different stages) are underway with two museums to get access to their collection of meteorites.

4. Theoretically driven search. The overarching goal of this work is to identify the universal trends of unconventional superconductors that can be used for a directed search of new superconducting materials. We found earlier a universal scaling relationship between the superfluid density and the product of $T_{c} \times \Delta$ ( $\Delta$ is the superconducting energy gap) in unconventional superconductors. We showed lately that this scaling is also present in organic superconductors. This now provides a theoretical framework for the directed search for new superconductors used by us and others.

5. Collaborations are underway in a variety of combinations with the other SuperSearch MURIs, individual researchers, Army Core of Engineers and science museums. For a comprehensive list see Table II.

6. New superconducting systems found. A substantial number of new materials systems were found which exhibit superconductivity at cryogenic temperatures. Improving the $T_{c}$ of these systems is underway. See Table III below.

\section{PRACTICAL RESULTS}

The results were summarized in 38 papers in first-rate refereed journals, were part of 8 $\mathrm{PhD}$ theses, presented as invited and contributed talks at major meetings, and had a major influence on the education of graduate students and postdoctoral fellows. 
This research has also been crucial in the education of several PhD students impacting 8 theses works in different ways. Several (19) postdoctoral fellows have contributed partially to the research outlined above and 7 visitors contributed, sometimes free of cost. It is important to highlight that much of the research being done under this project benefits from extensive collaborations with chemist, physicists and engineers at UCSD and other institutions, thus the young investigators are exposed to an important modality of collaborative research.

The graduate students and postdocs associated with this project that have finished their tenure, are employed in industry, national labs and academia. They are also developing independent research in related fields.

\section{Archival Publications (published- project entirety)}

1. Towards a Two-Dimensional Superconducting State of $\mathrm{La}_{2-x} \mathrm{Sr}_{2} \mathrm{CuO}_{4}$ in a Moderate External Magnetic Field, A. Shafgans, A. LaForge, S. Dordevic, M. Qazilbash, W. Padilla, K. Burch, Z. Li, S. Komiya, Y. Ando, and D. Basov, Phys. Rev. Lett. 104, 157002 (2010).

2. Superconductivity at $7.3 \mathrm{~K}$ in $T i_{2} I n N$, A. Bartolozo, G. Serrano, A. Serquis, D. Rodrigues Jr., C. A. M. dos Santos, Z. Fisk, A. Machado. Solid State Commun. 150, 1364 (2010).

3. Breakdown of the Universal Josephson Relation in Spin-ordered Cuprate Superconductors, A. A. Schafgans, C. C. Homes, G. D. Gu, Seiki Komiya, Yoichi Ando, and D. N. Basov, Phys. Rev. B 82, 100505(R) (2010)

4. Methodology and Search for Superconductivity in the La-Si-C system, J. de la Venta, A. Basaran, T. Grant, A. Machado, M. Suchomel, R. Weber, Z. Fisk, and Ivan K. Schuller, Supercond. Sci. Technol. 24, 075017 (2011)

5. Manifesto for Higher $T_{c}$, D. Basov and A. Chubukov, Nature Physics 7, 272 (2011)

6. Incoherent c-Axis Interplane Response of the Iron Chalcogenide FeTe $e_{0.55} \mathrm{Se}_{0.45}$ Superconductor from Infrared Spectroscopy, S.J. Moon, C.C. Homes, A.Akrap, Z.J. $\mathrm{Xu}$, J.S. Wen, Z.W. Lin, Q. Li, G.D. Gu, and D.N. Basov, Phys. Rev. Lett. 106, 217001 (2011).

7. Evidence of a Precursor Superconducting Phase at Temperatures as High as $180 \mathrm{~K}$ in $\mathrm{RBa}_{2} \mathrm{Cu}_{3} \mathrm{O}_{7-\delta}$ ( $\left.R=Y, G d, \mathrm{Eu}\right)$ Superconducting Crystals from Infrared Spectroscopy, A. Dubroka, M. Rossle, K.W. Kim, V. K. Malik, D. Munzar, D. N. Basov, A.A. Schafgans, S. J. Moon, C. T. Lin, D. Haug, V. Hinkov, B. Keimer, Th. Wolf, J. G. Storey, J. L. Tallon, and C. Bernhard, Phys. Rev Lett. 106, 047006 (2011).

8. Ultrahigh Vacuum Sample Mount for X-ray Photoelectron Spectroscopy up to very High Temperature 150-1400 K, M.S. Williamsen, S.K. Ray, Y. Zou, J. Dudek, S. Sen, M. Bissen, L. Kretsch, V.R. Palkar, M.F. Onellion, and P. Guptasarma, J. Vac. Sci. Technol. A 29, 031602 (2011).

9. Electrodynamics of Correlated Electron Materials, D. N. Basov, Richard D. Averitt, Dirk van der Marel, Martin Dressel, and Kristjan Haule, Rev. Mod. Phys. 83, 471 (2011).

10. Superconductivity in $\mathrm{Mo}_{3} \mathrm{SiB}_{2}$, A.J.S.Machado, A.M.S.Costa, C.A.Nunes, C.A.M.dos Santos, T.Grant and Z. Fisk, Solid State Comm. 151,1455 (2011). 
11. Superconductivity in $\mathrm{Th}_{3} \mathrm{Ni}_{5} \mathrm{C}_{5}$, A.J.S.Machado, T.Grant and Z.Fisk, Supercond. Sci. Technol. 24, 095007 (2011).

12. Superconductivity to $11.5 \mathrm{~K}$ in $\mathrm{Th}_{2-x} \mathrm{Sc}_{x} \mathrm{NiC}$, A.J.S.Machado, T.Grant and Z.Fisk (in preparation).

13. Crystal Structure and Properties of $\mathrm{Tb}(\mathrm{Mn}, \mathrm{Cu}) \mathrm{O}_{3}$, S.K. Ray, M.S. Williamsen, S. Sen, Y. Zou, P. Guptasarma (in preparation).

14. Properties of Superconducting La-Si-C, S. Sen, S.K. Ray, J.A. Dudek, M.S. Williamsen, Y. Zou, and P. Guptasarma (in preparation).

15. Search for Superconductivity in V-VI compounds, S. Sen and P. Guptasarma (in preparation).

16. Phase Spread Alloy Fabrication and Characterization, M. Marsh, J. de la Venta, A. Barasan, D. N. Basov, S. Dietze, O. Shpyrko, I. K. Schuller (in preparation).

17. Insulator-to-metal transition and correlated metallic state of $\mathrm{V}_{2} \mathrm{O}_{3}$ investigated by optical spectroscopy, M.K. Stewart, D. Brownstead, S. Wang, K.G. West, J.G. Ramirez, M.M. Qazilbash, N.B. Perkins, Ivan K. Schuller, D. Basov, Phys. Rev. B, 85(20), 205113 (2012).

18. Electron Spin Resonance of the Intermetallic Antiferromagnet Euln ${ }_{2} \mathrm{As}_{2}$, P.F.S. Rosa, C. Adriano, T.M. Garitezi, R.A. Ribeiro, Z. Fisk, P.G. Pagliuso, Phys. Rev. B, 89(9), 094408 (2012).

19. $\mathrm{Th}_{2} \mathrm{NiC}_{2}:$ A Low Density of States Superconductor, A.J.S. Machado, T. Grant, Z. Fisk, Supercond. Sci. Technol., 25(4), 045010 (2012).

20. Infrared Measurement of the Pseudogap of P-Doped and Co-Doped High-Temperature BaFe2As2 Superconductors, S.J. Moon, A.A. Schafgans, S. Kasahara, T. Shibauchi, T. Terashima, Y. Matsuda, M. A. Tanatar, R. Prozorov, A. Thaler, P. C. Canfield, A.S. Sefat, D. Mandrus, and D.N. Basov, Phys. Rev. Lett. 109, 027006 (2012).

21. Electronic Correlations and Unconventional Spectral Weight Transfer in the HighTemperature Pnictide BaFe ${ }_{2-x} \mathrm{CO}_{x} \mathrm{As}_{2}$ Superconductor Using Infrared Spectroscopy, A. A. Schafgans, S. J. Moon, B. C. Pursley, A. D. LaForge, M. M. Qazilbash, A. S. Sefat, D. Mandrus, K. Haule, G. Kotliar, and D. N. Basov, Phys. Rev. Lett. 108, 147002 (2012).

22. Corrigendum: Methodology and Search for Superconductivity in the La-Si-C System, J. de la Venta, Ali C. Basaran, T. Grant, A.J.S. Machado, M.R. Suchomel, R.T. Weber, Z. Fisk and Ivan K. Schuller, Supercond. Sci. Technol. 25, 049501 (2012).

23. Magnetism and the Absence of Superconductivity in the Praseodymium-Silicon System Doped with Carbon and Boron, J. de la Venta, A.C. Basaran, T. Grant, J.M. GallardoAmores, J.G. Ramirez, M.A. Alario-Franco, Z. Fisk, I.K. Schuller, J. Magn. Magn. Mater., 340, 27 (2013).

24. Ferromagnetism in Partially Oxidized $\mathrm{CuCl}$, T. Saerbeck, J. Pereiro, J.Wampler, J. Stanley, J. Wingert, O.G. Shpyrko, and Ivan K. Schuller, J. Magn. Magn. Mater., 346, 161 (2013).

25. Sharp Raman Anomalies and Broken Adiabaticity at a Pressure Induced Transition from Band to Topological Insulator in $\mathrm{Sb}_{2} \mathrm{Se}_{3}$, A. Bera, L. Pal, D.V. Muthu, S. Sen, P. Guptasarma, U.V. Waghmare, A.K. Sood, Phys. Rev. Lett., 110, 107401 (2013). 
26. Electron Spin Resonance of the Intermetallic Antiferromagnet Euln ${ }_{2} A_{2}$, P.F.S. Rosa, C. Adriano, T.M. Garitezi, R.A. Ribeiro, Z. Fisk, P.G. Pagliuso, Phys. Rev. B, 89(9), 094408 (2012).

27. Evolution of $\mathrm{Eu}^{2+}$ Spin Dynamics in $B a_{1-x} E u_{x} \mathrm{Fe}_{2} A s_{2}$, P.F.S. Rosa, C. Adriano, W. Iwamoto, T.M. Garitezi, T. Grant, Z. Fisk, P.G. Pagliuso, Phys. Rev. B., 88(15), 159907 (2013).

28. Critical Current Density and Flux Pinning in $\mathrm{Zr}_{0.96} \underline{V}_{0.04} \underline{B}_{2}$ Superconductor with $\mathrm{AIB}_{2}$ Structure, Soon-Gil Jung, J. Vanacken, V.V. Moshchalkov, S.T. Renosto, C.A.M. dos Santos, A.J.S. Machado, Z. Fisk, J. Albino Aguiar, J. Appl. Phys., 114(13), 133905 (2013).

29. Conduction Electron Spin Resonance in $A I B_{2}$, L.M. Holand, L. Mendonca-Ferreira, R.A. Ribeiro, J.M. Osorio-Guillen, B.M. Dalpian, K. Kuga, S. Nakatsuji, Z. Fisk, R.R. Urbano, P.G. Pagliuso and C. Rettori, J. Phys.: Condens. Matter, 25 (21), 216001 (2013).

30. Do Organic and other Exotic Superconductors Fail Universal Scaling Relations? S.V. Dordevic, D.N. Basov \& C.C. Homes, Nature - Scientific Reports 3, 1713 (2013).

31. Interlayer Coherence and Superconducting Condensate in the c-Axis Response of Optimally Doped $\mathrm{Ba}\left(\mathrm{Fe}_{1-x} \mathrm{CO}_{x}\right)_{2} \mathrm{As}_{2}$ High-Tc Superconductor Using Infrared Spectroscopy, S.J. Moon, A.A. Schafgans, M.A. Tanatar, R. Prozorov, A. Thaler, P.C. Canfield, A.S. Sefat, D. Mandrus, and D.N. Basov, Phys. Rev. Lett. 110, 097003 (2013).

32. Magnetic Field Modulated Microwave Spectroscopy Across Phase Transitions and the Search for New Superconductors, J. G. Ramirez, Ali C. Basaran, J. de la Venta, J. Pereiro and Ivan K. Schuller. Rep. Prog. Phys. 77, 093902 (2014).

33. Superconductivity in Non-centrosymmetric $T h C_{0} C_{2}$, T. Grant, A.J.S. Machado, D.J. Kim and Z. Fisk, Supercon. Sci. Technol., 27, 035004 (2014).

34. Field-enhanced Magnetic Moment in Ellipsoidal Nano-hematite, V. Malik, S. Sen, D.R Gelting, M. Gajdardziska-Josifovska, M. Schmidt, P. Guptasarma, Mater. Res. Express 1 (2014) 026114.

35. Search for Superconductivity in $\mathrm{Fe}_{1+d}$ Te: Role of Oxidation State, D. R. Gelting, N. P. Smith, S. Sen, M. Schofeld, A. Basaran, I. K. Schuller, M. Gajdardziska-Josifovska, P. Guptasarma, to be communicated Phys. Rev. B, available as preprint (2014).

36. Infrared Pseudogap in Cuprate and Pnictide High-temperature Superconductors, S. J. Moon, Yunsang Lee, A.A. Schafgans, A.V. Chubukov, S. Kasahara, T. Shibauchi, T. Terashima, Y. Matsuda, M.A. Tanatar, R. Prozorov, A. Thaler, P.C. Canfield, A.S. Sefat, D. Mandrus, K. Segawa, Y. Ando, and D. N. Basov, Phys. Rev. B. 90, 014503 (2014).

37. Near-field Techniques for Probing Collective Modes of Anisotropic Superconducting Thin Films, H. T. Stinson, J.S. Wu, B.Y. Jiang, Z. Fei, A.S. Rodin, B. Chapler, A.S. Mcleod, A. Castro Neto, Y.S. Lee, M. M. Fogler, and D.N. Basov (Under review in PRB).

38. Search for Superconductivity in Extraterrestrial Materials: A Most Unusual Fishing Expedition, S. Guenon, J. G. Ramirez, Ali C. Basaran, M. Thiemens, S. Taylor, and Ivan K. Schuller (under review Scientific Reports) 
Changes in research objectives, if any: None

Change in AFOSR program manager, if any: None

Extensions granted or milestones slipped, if any: None

Include any new discoveries, inventions, or patent disclosures during this reporting period (if none, report none):

Table I: Systems explored (superconductors and non-superconductors).

\begin{tabular}{|c|c|c|c|}
\hline OXIDES & CALCOGENIDES & SILICIDES & OTHERS \\
\hline $\mathrm{MoSrEuCuO}$ & $\mathrm{Bi}_{2} \mathrm{Te}_{3}$ & $\mathrm{Eu}-\mathrm{Si}$ & FePc (Phthalocyanine) \\
\hline $\mathrm{GdBa}_{2} \mathrm{Cu}_{3} \mathrm{O}_{\mathrm{x}}$ & $\mathrm{FeTe}_{0.65} \mathrm{Se}_{0.35}$ & $\mathrm{LaFe}_{2} \mathrm{Si}_{2}$ & $\mathrm{H}_{2} \mathrm{O}$ treated Graphite \\
\hline $\mathrm{SmBa}_{2} \mathrm{Cu}_{3} \mathrm{O}_{\mathrm{x}}$ & FeSe:K & Eu-Si-Nb & HOPG (Graphene) \\
\hline $\mathrm{MnO}$ & FeTe & $\mathrm{Cu}_{3} \mathrm{Si}$ & Teflon \\
\hline $\mathrm{V}_{2} \mathrm{O}_{3}$ & $\mathrm{Bi}_{2} \mathrm{Te}_{3} \mathrm{Cux}$ & CARBIDES & Irradiated $\mathrm{Si}$ \\
\hline $\mathrm{Pb}-\mathrm{Mo}-\mathrm{Cl}-\mathrm{O}$ & $\mathrm{Bi}_{2} \mathrm{Se}_{3} \mathrm{Cu}_{\mathrm{x}}$ & Pr-Si-C & $\mathrm{Nb}_{3} \mathrm{Ge}$ \\
\hline $\mathrm{YBa}_{2} \mathrm{Cu}_{3} \mathrm{O}_{7}$ & $\mathrm{Bi}_{2} \mathrm{Se}_{3}$ & Eu-Si-C & $\mathrm{ErRh}_{4} \mathrm{~B}_{4}$ \\
\hline $\mathrm{Bi}_{2} \mathrm{Sr}_{2} \mathrm{CaCu}_{2} \mathrm{O}_{8}(\mathrm{UD}, \mathrm{OD})$ & $\mathrm{Sb}_{2} \mathrm{Se}_{3}$ & V-Si-C & (Ga,Mn)As \\
\hline $\mathrm{CuO}$ & $\mathrm{ZrSe}_{2}$ & $\mathrm{Sm}-\mathrm{Si}-\mathrm{C}$ & $\mathrm{Hf}(\mathrm{FeCo}) \mathrm{P}$ \\
\hline $\mathrm{Y}_{1-\mathrm{x}} \mathrm{Ca}_{\mathrm{x}} \mathrm{CrO}_{3}$ & $\mathrm{Fe}-\mathrm{Te}-\mathrm{Se}$ & BORIDES & Hf-Fe-C-P \\
\hline $\mathrm{YCrO}_{3}$ & $\mathrm{Cu}-\mathrm{Se}-\mathrm{V}$ & $\mathrm{Eu}_{5} \mathrm{Si}_{3} \mathrm{~B}$ & \\
\hline $\mathrm{Fe}_{3} \mathrm{O}_{4}$ & CHLORIDES & $\mathrm{MgB}_{2}$ & \\
\hline $\mathrm{SiO}_{2}$ & $\mathrm{FeCl}_{2}$ & $\mathrm{TiB}_{2}$ & \\
\hline La-Fe-Ba-Bi-O & $\mathrm{CuCl} / \mathrm{Si}$ & $\mathrm{AlB}_{2}$ & \\
\hline $\mathrm{V}_{2} \mathrm{O}_{5}: \mathrm{Ti}$ & $\mathrm{CuCl}$ & $\mathrm{TiB}_{2}$ & \\
\hline $\mathrm{CaCuO}_{2} / \mathrm{SrTiO}_{3}$ & $\mathrm{CuCl}_{2}$ & $\mathrm{Eu}_{5} \mathrm{Si}_{3} \mathrm{~B}$ & \\
\hline $\begin{array}{l}(\mathrm{Mo} / \mathrm{Cu}) \mathrm{Sr}_{2} \mathrm{ReCu}_{2} \mathrm{O}_{\mathrm{x}}, \mathrm{RE}: \\
(\mathrm{Y}, \mathrm{Er} \& \mathrm{Tm})\end{array}$ & $\mathrm{Cu}-\mathrm{Se}-\mathrm{Cl}$ & $\mathrm{TiB}_{2}$ & \\
\hline
\end{tabular}

Table II: Worldwide service and collaborations.

\begin{tabular}{|c|c|}
\hline Collaborator & Institution \\
\hline M. A. Alario-Franco & Universidad Complutense de Madrid, Spain \\
\hline $\begin{array}{l}\text { M. Aronson } \\
\text { M. R. Beasley }\end{array}$ & $\begin{array}{l}\text { Stony Brook University, USA } \\
\text { Stanford University, USA }\end{array}$ \\
\hline D. Esquinazi & Universität Leipzig, Germany \\
\hline I. Felner & Jerusalem, Israel \\
\hline T. J. Haugan & The Air Force Research Lab., USA \\
\hline J. Hirsch & University of California - San Diego, USA \\
\hline G. Larkin & Florida International University, USA \\
\hline B. Maple & University of California - San Diego, USA \\
\hline S. Risbud & University of California - Davis, USA \\
\hline J. Sonier & Simon Fraser University, Canada \\
\hline S. Taylor & Cold Regions Lab., USA \\
\hline M. Thiemens & University of California - San Diego, USA \\
\hline R. Puzniak & Institute of Physics, Warsaw, Poland \\
\hline
\end{tabular}


Table III New superconductors, discovered by UCSD MURI team.

\begin{tabular}{|c|c|}
\hline BORIDES & $\underline{T_{c}(K)}$ \\
\hline $\mathrm{Nb}_{0.9} \mathrm{Zr}_{0.1} \mathrm{~B}$ & 11.2 \\
\hline $\mathrm{ZrNb}_{\mathrm{x}} \mathrm{B}$ & 9.0 \\
\hline $\mathrm{ZrV}_{\mathrm{x}} \mathrm{B}$ & 9.0 \\
\hline $\mathrm{ThNi}_{2} \mathrm{Si}_{2} \mathrm{~B}_{\mathrm{x}}$ & 8.5 \\
\hline Th(RE)B 4 (3 compounds) & 5.8 \\
\hline $\mathrm{Zr}_{0.98} \mathrm{Ni}_{0.2} \mathrm{~B}_{2}$ & 5.7 \\
\hline $\mathrm{Mo}_{5} \mathrm{Si}_{2} \mathrm{~B}$ (7 compounds) & 5.5 \\
\hline $\mathrm{Zr}_{0.99} \mathrm{Ta}_{0.01} \mathrm{~B}_{2}$ & 5.5 \\
\hline $\mathrm{Nb}_{0.9} \mathrm{Ni}_{0.1} \mathrm{~B}_{2}$ & 5.3 \\
\hline $\mathrm{Zr}_{0.99} \mathrm{Nb}_{0.01} \mathrm{~B}_{2}$ & 5.2 \\
\hline $\mathrm{Zr}_{0.91} \mathrm{Pt}_{0.09} \mathrm{~B}_{2}$ & 3.7 \\
\hline $\mathrm{W}_{2} \mathrm{NiB}_{2}$ & 3.5 \\
\hline $\mathrm{ThMoB}_{4}$ & 2.8 \\
\hline \multicolumn{2}{|l|}{ CALCOGENIDES } \\
\hline $\mathrm{ZrCu}_{\mathrm{x}} \mathrm{Te}_{1.5}$ & 10.0 \\
\hline $\mathrm{ZrV}_{\mathrm{x}} \mathrm{S}_{2}$ & $7.0-9.0$ \\
\hline $\mathrm{ZrV}_{\mathrm{x}} \mathrm{Se}_{2}$ & $7.0-9.0$ \\
\hline $\mathrm{ZrV}_{\mathrm{x}} \mathrm{Te}$ & $7.0-9.0$ \\
\hline \multicolumn{2}{|l|}{ CARBIDES } \\
\hline $\mathrm{ThCo}_{0.6} \mathrm{Ni}_{0.4} \mathrm{C}_{2}$ & 12.0 \\
\hline $\mathrm{Th}_{2-\mathrm{x}} \mathrm{Sc}_{\mathrm{x}} \mathrm{NiC}_{2}$ & $9.0-11.0$ \\
\hline $\mathrm{Th}_{2} \mathrm{NiC}_{2}$ & 8.5 \\
\hline $\mathrm{Sc}_{3} \mathrm{CoC}_{4}$ & 7.0 \\
\hline $\mathrm{ThNi}_{4} \mathrm{C}$ & 5.1 \\
\hline $\mathrm{Th}_{3} \mathrm{Ni}_{5} \mathrm{C}_{5}$ & 5.0 \\
\hline $\mathrm{Th}_{5} \mathrm{Ni}_{4} \mathrm{C}$ & 5.0 \\
\hline $\mathrm{ThCoC}_{2}$ & 2.7 \\
\hline $\mathrm{ThNiC}_{2}$ & 2.7 \\
\hline $\mathrm{YCoC}_{2}$ & 2.5 \\
\hline \multicolumn{2}{|l|}{ OTHERS } \\
\hline $\mathrm{Zr}_{2} \mathrm{CuSb}_{3}$ & 8.8 \\
\hline ZrVGe & 6.0 \\
\hline $\mathrm{HfV}_{2} \mathrm{Ga}_{4}$ & 4.0 \\
\hline $\mathrm{Y}_{3} \mathrm{NiCSi}_{2}$ & 3.8 \\
\hline ThSiGe & 3.4 \\
\hline $\mathrm{Y}_{5} \mathrm{Ni}_{2} \mathrm{Bi}$ & 3.3 \\
\hline CaCeIr & 3.0 \\
\hline
\end{tabular}

